\title{
Finite element simulation and experimental test of the wear behavior for self-lubricating spherical plain bearings
}

\author{
Yahong XUE ${ }^{1,2,3}$, Jigang CHEN ${ }^{1,2, *}$, Sumin GUO ${ }^{1,2}$, Qingliang MENG ${ }^{1,2}$, Junting LUO ${ }^{1,3}$ \\ ${ }^{1}$ School of Mechanical Engineering, Yanshan University, Qinhuangdao 066004, China \\ ${ }^{2}$ Aviation Key Laboratory of Science and Technology on Generic Technology of Self-Lubricating Spherical Plain Bearing, Yanshan University, \\ Qinhuangdao 066004, China \\ ${ }^{3}$ Education Ministry Key Laboratory of Advanced Forging and Stamping Technology and Science, Yanshan University, Qinhuangdao 066004, \\ China
}

Received: 27 August 2017 / Revised: 04 November 2017 / Accepted: 26 December 2017

(C) The author(s) 2018. This article is published with open access at Springerlink.com

\begin{abstract}
In this study, based on the classical Archard adhesion wear theory, a three-dimensional finite element model was established, with the aim of simulating the failure process of self-lubricating spherical plain bearings in the swinging wear condition. The results show that the self-lubricating spherical plain bearings go through two different stages during the wear process, namely, initial wear stage and stable wear stage. Because the large contact points wear out during the initial wear stage, the maximum contact pressure decreases as the test period increases. The relatively larger wear depth region shows elliptical distribution, and the maximum distribution appears in the central contact area. The wear depth reaches $0.974 \mathrm{~mm}$ after swinging 25,000 times. PTFE fibers, which possess a good friction performance but poor abrasion resistance, abundantly exist on the friction surfaces of the fabric liner. Consequently, the friction torque during the initial wear stage is slightly smaller than the friction torque during the stable wear stage; however, the wear rate during the initial wear stage is high. The reliability and effectiveness of the finite element model are verified by experiment. The developed finite element model can be used for the analysis of the wear mechanisms of bearings and the prediction of the service life of bearings.
\end{abstract}

Keywords: spherical plain bearing; wear mechanisms; wear depth; contact pressure; simulation

\section{Introduction}

A self-lubricating spherical plain bearing, as a type of spherical sliding bearings, comprises a metal inner ring, outer ring, and self-lubricating fabric liners. Owing to their compact structure, small friction coefficient, and strong impact resistance, self-lubricating spherical plain bearings have been widely used in aircraft landing gears, railway locomotives, brake vibration, and in shock absorption system [1-4].

At present, it is generally believed that the abrasive wear of fabric liners is the main reason for the failure of self-lubricating spherical plain bearings. The wearing of fabric liners enlarges the clearance between the inner and outer rings of self-lubricating spherical plain bearings, thus resulting in the vibration of bearings, low-working accuracy, and even the failure of the bearings during their service process [5-7].

Experimental exploration is the main method for investigating the friction and wear properties of self-lubricating spherical plain bearings at present [8-10]. In this method, the mechanism of wear failure is investigated by observing macroscopic phenomena such as the morphology and composition change of worn surfaces. However, this experimental exploration is not only time-consuming and costly but also

* Corresponding author: Jigang CHEN, E-mail: 24000082@qq.com 
unsatisfactory when it comes to practical problems such as uneven stress distributions or changeable working loads during the wear lifespan of fabric liners [11-15].

Recently, simulation technology based on the finite element method has been widely used to investigate wear problems [16-20]. Bortoleto et al. [21] used finite element software to write user subroutines, and simulated the material removal process of material in pin-on-plate tests based on the Archard wear model. Although establishing the model and writing the subprogram were very complicated, the analysis results indicated that the complex nonlinear wear process could be simulated with a series of discrete quasi static models. Shen et al. [22] established a two-dimensional finite element wear model of self-lubricating spherical plain bearings, which provided an effective way of predicting the wear life of mechanical components. However, the two-dimensional model could not reflect the $3 \mathrm{D}$ contact pressure distributions on the whole wear surface. Lu et al. [23] investigated the influences of motion types of the bearings on the distributions of contact pressure by establishing a 3D simplified model. However, this model could not simulate the wear profile and progressive wear process of the bearings.

In this paper, a 3D finite element model of selflubricating spherical plain bearings was established to simulate the wear behavior of bearings under swing motion. Based on the analysis of the simulation and experimental tests, the wear mechanism of the fabric liner was revealed.

\section{Archard wear model of the fabric liner}

\subsection{Archard adhesive wear theory}

The essence of the wear problem is the material loss produced at the contact surface when relative motion occurs. At present, the Archard adhesive wear model is generally used to calculate the wear loss [24]:

$$
V=\frac{K}{H} F_{\mathrm{n}} L
$$

where $V$ is the wear volume, $K$ is the adhesive wear factor, $H$ is the hardness of the material, $F_{n}$ is the normal load, and $L$ is the relative sliding distance of worn surfaces.

Regarding engineering application, the wear depth offers more practical significance. Therefore, a differential form of the Archard wear model can be obtained by dividing both sides of Eq. (1) by a small contact area $\Delta s$ :

$$
\frac{\mathrm{d} V}{\Delta s}=\frac{K}{H} \frac{F_{\mathrm{n}}}{\Delta s} \mathrm{~d} L
$$

where $\mathrm{d} V / \Delta s$ is the wear depth $\mathrm{d} h, F_{\mathrm{n}} / \Delta s$ is the local contact pressure $P$, and $K / H$ is the linear wear factor $K_{\mathrm{d}}$. Here, $\mathrm{d} L$ can be replaced by the product of the relative sliding velocity $v$ and test time $\mathrm{d} t$. Thus, the local increment of wear depth can be achieved by the following equation:

$$
\frac{\mathrm{d} h}{\mathrm{~d} t}=K_{\mathrm{d}} P v
$$

The liner wear factor $K_{d}$ is generally obtained by experimental methods. However, usually the liner wear factor $K_{\mathrm{d}}$ varies with the contact pressure $P$ and relative sliding velocity $v$. Taking into account the influence of the relative sliding velocity and contact pressure, Eq. (3) can be modified, and the wear rate can be expressed as follows:

$$
w=K_{\mathrm{d}} P^{m} v^{n}
$$

where $w$ is the wear rate, $m$ is the pressure exponent, and $n$ is the velocity exponent.

\subsection{Pin-on-plat sliding wear test of the fabric liner}

In order to obtain the Archard wear model of fabric liners, the 3-level orthogonal test was carried out on fabric liners under different loads $(50 \mathrm{MPa}, 75 \mathrm{MPa}$, and $100 \mathrm{MPa})$ and sliding velocities $(1.896 \mathrm{~mm} / \mathrm{s}$, $2.528 \mathrm{~mm} / \mathrm{s}$, and $3.160 \mathrm{~mm} / \mathrm{s}$ ). The wear test was carried out on the friction and wear testing machine. The wear form was a pin-on-plate reciprocating sliding wear. The upper sample was a cylindrical pin with a diameter of $4 \mathrm{~mm}$ and a length of $12 \mathrm{~mm}$. This testing machine and schematic diagram of pin-on-plate reciprocating sliding wear test are shown in Fig. 1. Before the wear test, the fabric liners were adhered to steel plates with phenolic-acetal resin. The changes of wear depth with time were recorded automatically by 
the wear testing machine, and the results are shown in Fig. 2.
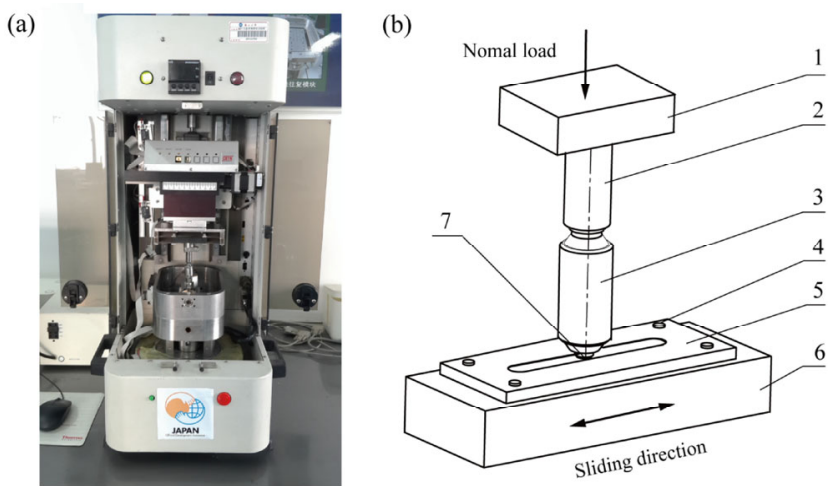

1. force sensor, 2. suspension, 3. pin holder, 4. sample clamp, 5. flat sample, 6. reciprocating stage, 7 . cylindrical pin.

Fig. 1 Physical diagram and schematic diagram of wear test of fabric liners: (a) photograph of the friction and wear tester, and (b) schematic diagram of pin-on-plate reciprocating sliding wear test.
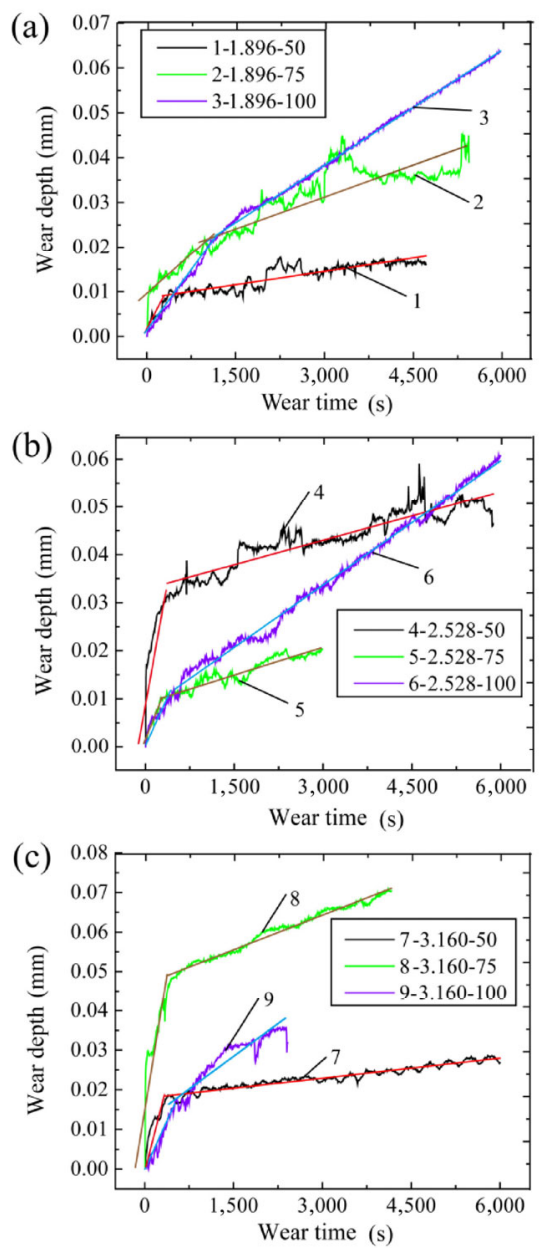

Fig. 2 Variation curves of wear depth of fabric liners under different pressures and velocities: (a) $1.896 \mathrm{~mm} / \mathrm{s}$; (b) $2.528 \mathrm{~mm} / \mathrm{s}$; and (c) $3.160 \mathrm{~mm} / \mathrm{s}$.
It can be seen from Fig. 2 that the wear curves of fabric liners consist of two stages. During the initial wear stage, the wear of fabric liners is fast and the plastic deformation on the wear surface is large. These lead to an increase in the local temperature and affirm adhesion. During the stable wear stage, the elastic-plastic contact conditions are established on wear surfaces, and thus the wear on the surfaces of fabric liners becomes slower. The two slopes on the wear curves are calculated, and the calculated results are taken as the wear rate of the two wear stages of the fabric liner. The wear rate of the initial wear stage and stable wear stage of fabric liners under different pressures and sliding velocities are shown in Tables 1 and 2 , respectively.

The wear rates shown in Tables 1 and 2 are fitted using a formula fitting software. The Archard wear models of fabric liners during the initial wear stage and the stable wear stage are obtained as follows:

$$
\begin{aligned}
& w_{1}=K_{\mathrm{d}} \cdot P^{m} \cdot V^{n}=2.415 \times 10^{-8} \cdot P^{1.54} \cdot V^{-0.499} \\
& w_{2}=K_{\mathrm{d}} \cdot P^{m} \cdot V^{n}=5.32 \times 10^{-10} \cdot P^{0.94} \cdot V^{0.98}
\end{aligned}
$$

\section{Finite element modeling and simulation}

\subsection{Basic definition}

Taking XRA12 self-lubricating spherical plain bearing as an example, the finite element model of a self-

Table 1 Wear rate $(\mathrm{mm} / \mathrm{s})$ of fabric liners in initial wear stage.

\begin{tabular}{cccc}
\hline $\begin{array}{c}\text { Sliding } \\
\text { velocity }(\mathrm{mm} / \mathrm{s})\end{array}$ & 50 & 75 & 100 \\
\hline 1.896 & $18.137 \mathrm{E}-6$ & $11.307 \mathrm{E}-6$ & $17.124 \mathrm{E}-6$ \\
2.528 & $55.214 \mathrm{E}-6$ & $35.185 \mathrm{E}-6$ & $25.214 \mathrm{E}-6$ \\
3.160 & $38.231 \mathrm{E}-6$ & $61.889 \mathrm{E}-6$ & $27.384 \mathrm{E}-6$ \\
\hline
\end{tabular}

Table 2 Wear rate $(\mathrm{mm} / \mathrm{s})$ of fabric liners in stable wear stage.

\begin{tabular}{rrrc}
\hline $\begin{array}{l}\text { Sliding } \\
\text { velocity }(\mathrm{mm} / \mathrm{s})\end{array}$ & 50 & 75 & 100 \\
\hline 1.896 & $1.90262 \mathrm{E}-6$ & $4.19248 \mathrm{E}-6$ & $6.44197 \mathrm{E}-6$ \\
2.528 & $3.58619 \mathrm{E}-6$ & $3.80271 \mathrm{E}-6$ & $8.78264 \mathrm{E}-6$ \\
3.160 & $1.59565 \mathrm{E}-6$ & $6.18368 \mathrm{E}-6$ & $9.99676 \mathrm{E}-6$ \\
\hline
\end{tabular}


lubricating spherical plain bearing in swinging wear tests is established. The dimensions, motion type and finite element mesh model of self-lubricating spherical plain bearing are shown in Fig. 3. As displayed in Fig. 3(b), $\theta_{0}$ indicates the maximum swing motion angle, which is $25^{\circ}$. The numbers $1-4$ in Fig. 3(b) as well as the arrow directions indicate the four steps in one swing cycle and swing directions of the pin, respectively. The swing frequency and swing times are, respectively, $0.2 \mathrm{~Hz}$ and 25,000 revolutions. To simulate the experimental conditions of the bearing system, a loading plate and a pin are also implemented in the modeling, both of which are considered as flexible bodies. The radial load applied on the loading plate is $18 \mathrm{kN}$.

\subsection{Materials, contacts and wear definition}

The inner ring is made of $9 \mathrm{Cr} 18$ stainless steel and the outer ring is made of $17-4 \mathrm{PH}$ stainless steel. The fabric liner is anisotropic material, which can use spherical coordinates to define its anisotropic material properties. The material properties of the bearing are shown in Table 3.

The bonding contact is set up between the spherical surface of the outer ring and bonding surface of the liner, as well as between the cylinder surface of the outer ring and loading plate. A bonding contact is also defined between the pin and the inner ring. Hence, the inner ring rotates with the pin. Frictional contact between the friction surface of the fabric liner (as contact surface) and the spherical surface of the inner ring (as target surface) is defined. The friction coefficient is set as 0.08 , which was obtained from the pin-on-plat sliding wear test of the fabric liner. The contact elements and target elements are defined as CONTA173 and CONTA174, respectively, because they support modeling wear.

To activate the wear in the contact surface, three wear parameters (liner wear factor $K_{d}$, pressure exponent $m$ and velocity exponent $n$ ) are defined in the material model via the TB command and assigned to the contact elements of the frictional contact. The parameters of $K_{d}, m$ and $n$ during the initial wear stage are expressed in Eq. 5, namely $K_{d}=2.415 \times 10^{-8}$, $m=1.54$ and $n=-0.499$. Similarly, the parameters of $K_{\mathrm{d}}, m$ and $n$ during the stable wear stage are expressed in Eq. 6, namely $K_{\mathrm{d}}=5.32 \times 10^{-10}, m=0.94$ and $n=0.98$. During the swing process of the spherical bearing, the wear occurs on both the fabric liner and inner ring. Because the wear loss on the spherical surface of the inner ring is very small compared with that of the fabric liner, only mass loss of the fabric liner is considered in the simulation.

\subsection{Steps, load, and boundary conditions definition}

The analysis type is set as "static, structural". Owing to the large deformation of the fabric liner, the geometric nonlinear effect is considered.

The swinging wear analysis of self-lubricating spherical plain bearing can be divided into 3 steps. The first step is to establish a stable contact relationship between the contact surfaces of the tested bearing and gradually apply the radial load. Thus, an equivalent radial load of $18 \mathrm{kN}$ is gradually applied to the loading

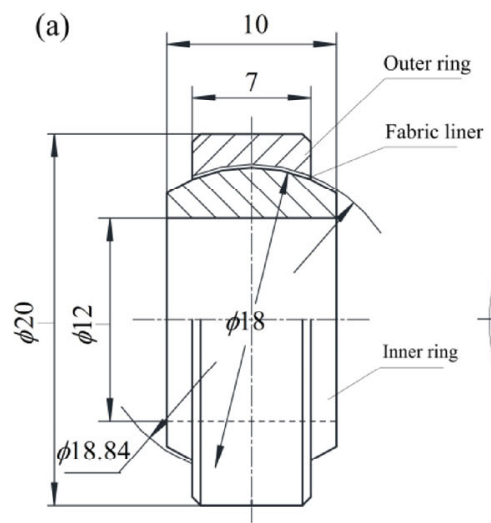

(b)

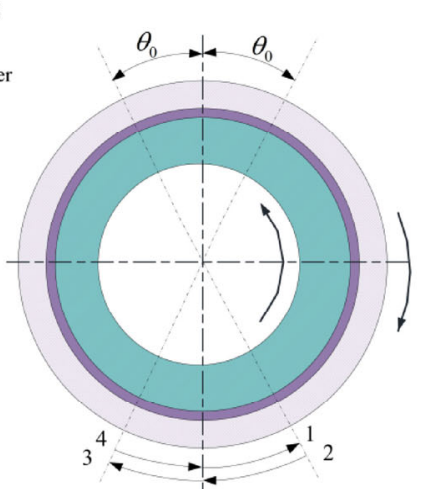

(c)

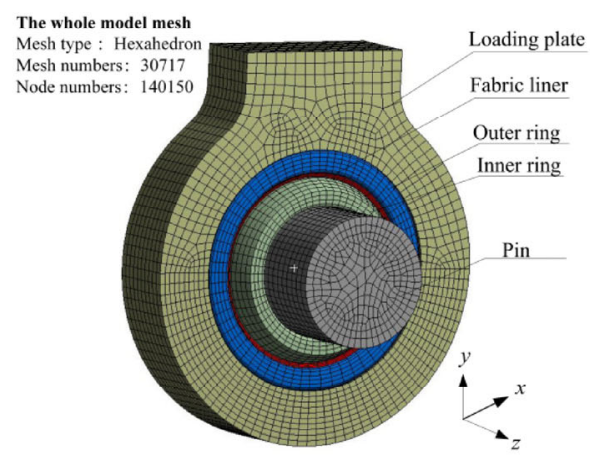

Fig. 3 The schematic diagram of dimensions, motion type and finite element mesh model of the test bearing: (a) dimensions of XRA12 self-lubricating spherical plain bearing, (b) swing motion steps of inner ring, and (c) finite element mesh model. 
Table 3 The mechanical properties of self-lubricating spherical plain bearing.

\begin{tabular}{cccc}
\hline Elastic constants & Outer ring & Inner ring & Fabric liner \\
\hline$E_{1}(\mathrm{GPa})$ & 210 & 203.89 & 52.04 \\
$E_{2}(\mathrm{GPa})$ & - & - & 4.71 \\
$v$ & 0.24 & 0.28 & 0.37 \\
$G_{12}(\mathrm{GPa})$ & - & - & 1.84 \\
$G_{23}(\mathrm{GPa})$ & - & - & 3.45 \\
\hline
\end{tabular}

plate in the negative direction of the $y$-axis. The radial load is kept unchanged during the next two steps.

The second and third steps are mainly to simulate the swinging wear process of the bearing during the initial wear stage and stable wear stage, respectively. A joint rotation is applied on the pin in the $z$ direction, and it is defined as URZ $=25 \sin$ (72×time). To prevent the loading plate from rotating under the friction force, the displacement boundary conditions of the loading plate are defined as $\mathrm{UX}=\mathrm{UZ}=\mathrm{URZ}=0$ ( $\mathrm{U}$ and UR indicate the line displacement and the rotation displacement, respectively).

\subsection{Wear simulation routine}

To analyze the dynamical wear problem with finite element method, the entire wear increment is discretized into many wear steps. For each wear step, the contact pressure and relative sliding velocity are calculated according to the contact state of contact nodes. Thereafter, the wear depth in this wear step is obtained by Eqs. (5) and (6). Thus, the wear depth of each node is obtained from the Eq. (7):

$$
h_{j, i}=h_{j-1, i}+\Delta h_{j, i}
$$

where $\Delta h_{j, i}$ is the wear depth of node $i$ during the wear step $j, h_{j-1, i}$ is the total wear depth of node $i$ in the previous $j-1$ wear steps, and $h_{j, i}$ is the total wear depth of node $i$ in the previous $j$ wear steps.

In the finite element simulation, the material loss in the contact surface is simulated by moving the contact node along the opposite direction of the contact normal. However, the reposition of the contact node results in a loss of equilibrium or a distorted finite element mesh, and thus fails in achieving an optimal solution. Therefore, the mesh is updated when the node moves such that it exceeds a specific proportion of the height of the corresponding element. The boundary displacement method is widely used to update the mesh in finite element analysis [25]. Figure 4 shows the basic procedures for simulating the wear evolution process.

\section{Results and discussion}

\subsection{Contact pressure}

Figure 5 shows the contact pressure distribution of fabric liners during both wear stages. During the initial wear stage, the maximum contact pressure appears in the middle contact area, and the contact pressure decreases along both circumferential and width directions. The higher contact pressure zone demonstrates a continuous and elliptic distribution. Owing to the ongoing wearing process, the location of the maximum contact stress does not change. However, the magnitude of the maximum contact pressure drops from $226 \mathrm{MPa}$ to $218 \mathrm{MPa}$, and the distribution of contact stress is more uniform.

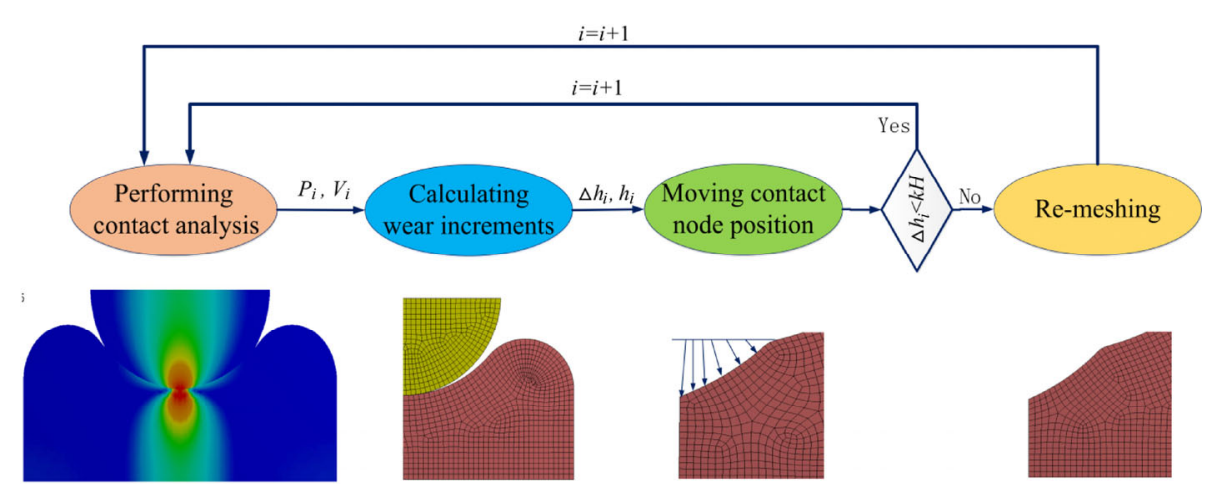

Fig. 4 Basic procedures for simulating the wear evolution process. 
(a) A: Static structral Swing number: 3000 Type: Contact stress Unit: $\mathrm{MPa}$

\begin{tabular}{|l}
226.21 \\
201.07 \\
-175.94 \\
-150.81 \\
125.67 \\
-100.54 \\
-75.402 \\
-50.268 \\
25.134 \\
$\mathbf{0} \quad$ Min
\end{tabular}

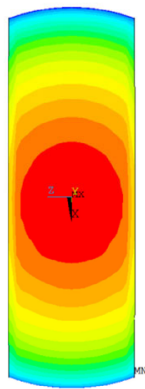

(b)

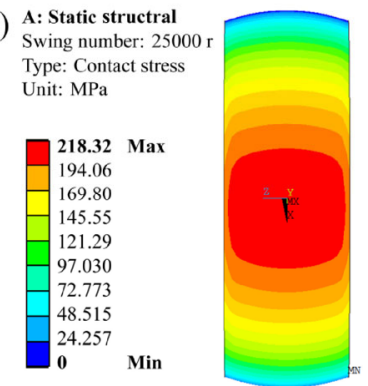

Fig. 5 Contact pressure distribution of fabric liners after different swing numbers: (a) 3,000 times and (b) 25,000 times.

The curve of the change in the maximum contact pressure with swing numbers is shown in Fig. 6. It can be seen from this figure that the maximum contact pressure decreases with increasing swing numbers. It reduces faster during the initial wear stage, and remains almost stable during the stable wear stage. The reason for this phenomenon can be explained as follows: under the action of radial load, the contact pressure at the small contact area of the contact center is large, and thus both the plastic deformation and wear speed here are large during the initial wear stage. As the running-in time extends, the contact point in the contact center is gradually flattened, and

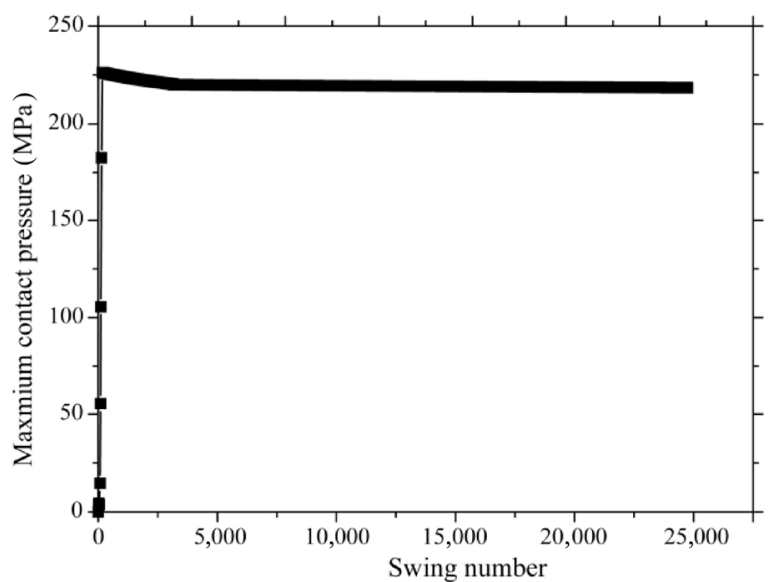

Fig. 6 The curve of maximum contact pressure with swing numbers.

the contact area gradually increases. Thus, the contact stress decreases and tends to be uniform.

\subsection{Wear morphology}

Figure 7 presents the wear depth distributions on the friction surface of the fabric liner after swinging 25,000 times. It can be seen from Fig. 7 that the wear depth is larger in the middle contact region and it decreases from the middle region in both

(a) A: Static structral
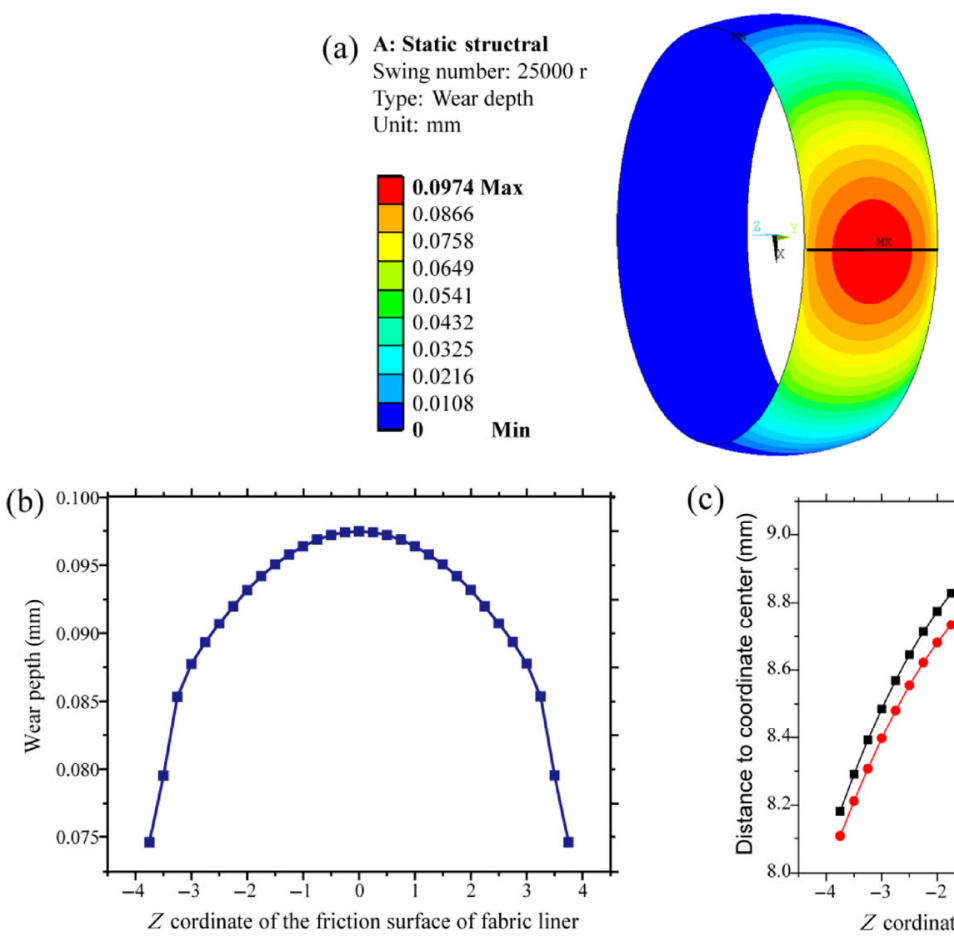

(c)

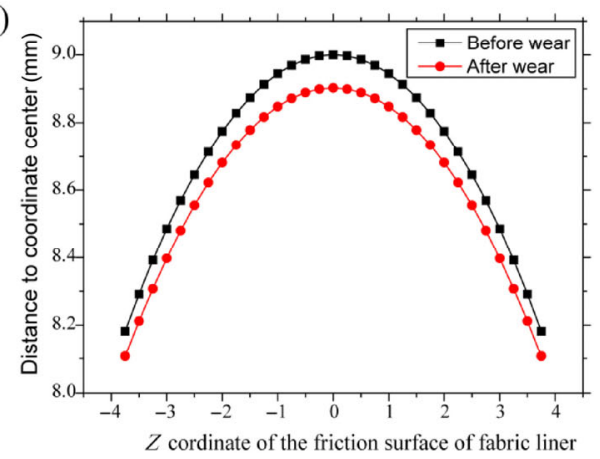

Fig. 7 Wear depth distributions on the friction surface of the fabric liner: (a) wear morphology obtained from simulation, (b) wear depth along the $\mathrm{z}$ direction, and (c) comparison of the friction surface of fabric liner before and after wear. 
circumferential and width directions. The relatively larger wear depth region also shows elliptic distribution. The maximum wear depth is $0.0974 \mathrm{~mm}$ and it occurs at the central contact region. The wear depth of the two border regions is relatively small, which is $0.0746 \mathrm{~mm}$. Therefore, it can be deduced that the wear failure of the fabric liner occurs first in the central contact region.

As indicated by Fig. 8, the wear depth of fabric liners varies with swing numbers. During the initial wear stage, the amount of wear depth presents a sharp increase. This indicates that the self-lubricating spherical plain bearings wear violently at this stage. When the swing number reaches approximately 3000, the wear rate tends to decrease with test period. Additionally, it maintains a relatively steady state over a long period of time. It can be inferred that the self-lubricating spherical plain bearing goes through two different stages during the whole wear process, namely initial wear stage and stable wear stage. As shown in Figs. 6 and 8, the change in contact pressure makes little contribution to the wear depth after the initial wear stage, and the wear rate remains almost constant. Hence, it can be inferred that the cumulative wear of the self-lubricating spherical plain bearing will reach $0.11 \mathrm{~mm}$ (the wear depth of bearing failure) after swinging 30,956 times. Therefore, the service life of the self-lubricating spherical plain bearing can be predicted.

\section{Wear test and results}

\subsection{Swinging wear test of self-lubricating spherical plain bearing}

The swinging wear test is conducted on a self-made service performance evaluation test machine of selflubricating spherical plain bearings. The photograph of the swinging wear tester and the schematic diagram of loading devices are shown in Fig. 9. The outer ring is fixed and the inner ring swings continuously along with the pin. The dynamics radial load tests were carried out according to the aeronautical standards (SAE AS 81820 and EN2755). The radial load applied by the loading plate is $18 \mathrm{kN}$. The swing frequency is $0.2 \mathrm{~Hz}$, and maximum swing angle is $25^{\circ}$. The

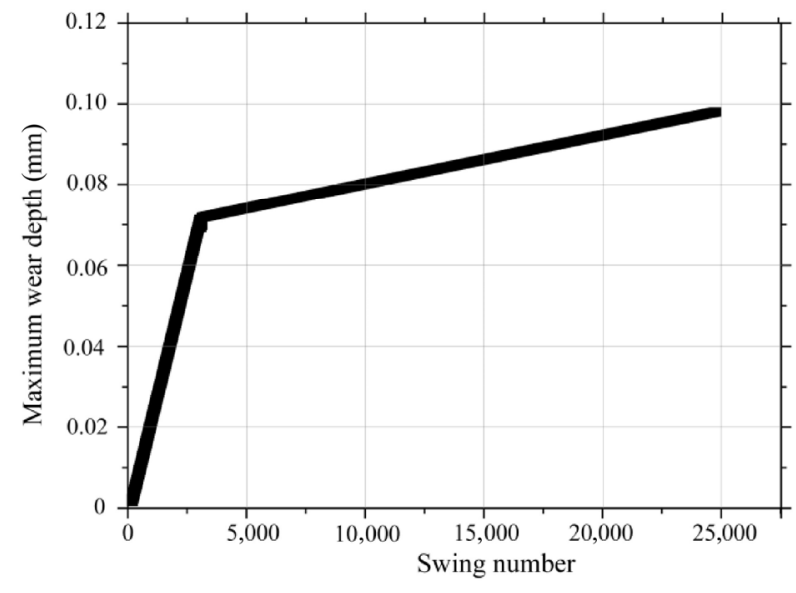

Fig. 8 The curve of the wear depth of fabric liners varies with swing numbers.
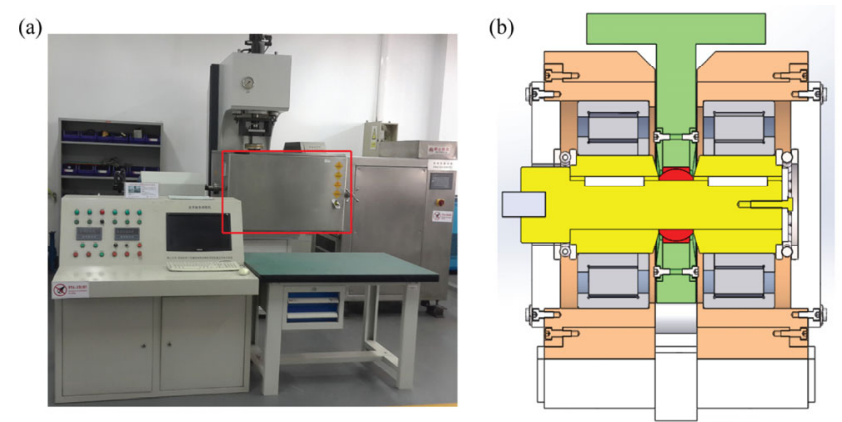

Fig. 9 Physical diagram and schematic diagram of swinging wear test of self-lubricating spherical plain bearing: (a) photograph of the swinging wear tester and (b) schematic diagram of loading devices.

experiments are carried out at room temperature. The friction torque is recorded automatically by a torque sensor in the test machine, and the wear depth of the fabric liner is measured by a displacement sensor installed under the tested bearing. After the wear test, the worn surface morphology of the fabric liner is observed by a confocal laser scanning microscope.

\subsection{Wear morphology of the fabric liner}

Figure 10 shows the worn surface morphology of the fabric liner. As seen in Fig. 10(a), the friction surface of the fabric liner is relatively smooth before the wear test, and the surface is covered with phenolic resin. The surface of the resin presents the indentation left when the fabric liner solidifies. Figure 10(b) shows that a wear scar exists in the middle contact region of the width direction after 25,000 times of swinging wear. Close to the ends of the bearing, the resin layer 

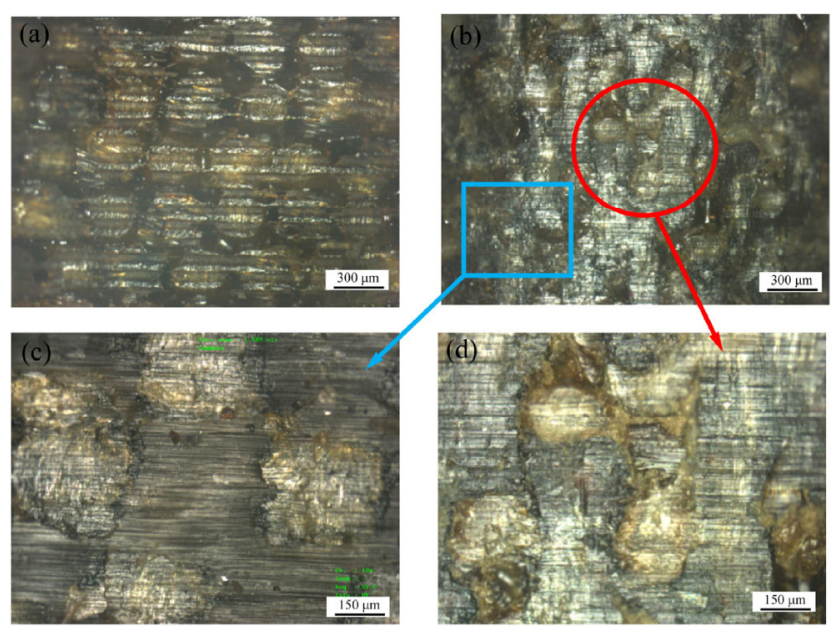

Fig. 10 The worn surface morphology of the fabric liner: (a) before wearing out, (b) after swinging 25,000 times, (c) the region closed to the end of the bearing, and (d) the middle contact region in the width direction.

on the surface of the liner has been worn off. Most of the surface area is covered with the black PTFE, and the yellow aramid fiber is faintly visible. This phenomenon can be explained as follows: PTFE fibers with poor wear resistance are easily worn out and form debris under africtional shearing force. The debris is pressed and filled in the pits of the friction surface. Because of the good tribological properties of PTFE material, a layer of PTFE lubricating film is gradually formed on the friction surface with increasing amount of PTFE fibers, which can prevent the direct contact between the inner ring and the fabric liner. Accordingly, the wear degree here is relatively small. However, because of the high contact pressure and frictional shearing force, the PTFE lubricating film in the middle contact region of the width direction is quickly fractured. A large number of yellow aramid fibers are exposed on the surface of the fabric liner. Thus, the wear degree here is comparatively serious, which is consistent with the finite element simulation results.

\subsection{Wear depth and friction torque}

Figure 11 presents the curve of the wear depth and friction torque of fabric liners varies with swing numbers. The wear depth is approximately $0.93 \mathrm{~mm}$ after swinging 25,000 times for self-lubricating spherical plain bearing. Compared with the finite element simulation results, the relatively error of the maximum wear depth is approximately $4.50 \%$. The friction torque in the initial wear stage is slightly smaller than that of the stable wear period. However, the wear rate during the initial wear stage is greater. The reason for this can be explained as follows: during the initial wear stage, a large number of PTFE fibers, which possess good friction performance and poor abrasion resistance, exist on the wear surface of the fabric liner. These fibers (mainly PTFE fibers) are extruded and deformed under the frictional shearing force. However, the debris produced in the friction process are filled in the interstices of the fabric liner surface. Therefore, the wear rate is larger at the initial wear stage, whereas the friction torque is smaller.

Owing to the development of the wear process, the proportion of PTFE fibers on the surface of the fabric liner decreases, while the proportion of aramid fibers increases. These aramid fibers possess excellent abrasion resistance. Moreover, the friction surface of the fabric liner is gradually filled up. Thus, the wear comes into a relatively stable stage, and the wear rate becomes small.
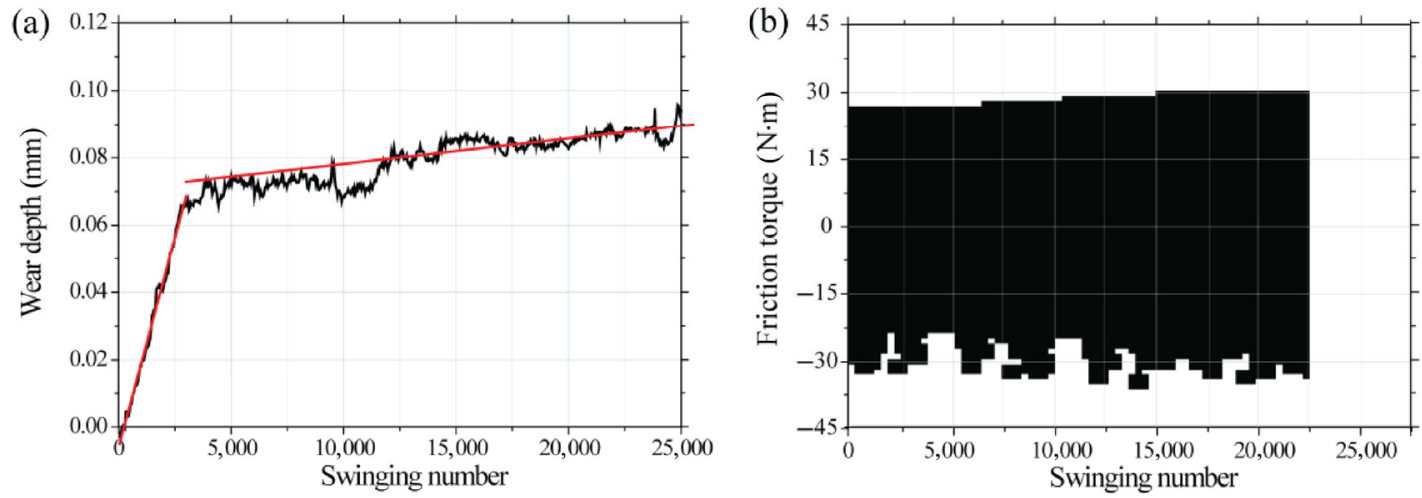

Fig. 11 Variation curves of the wear depth and friction torque with swing numbers: (a) wear depth and (b) friction torque. 


\section{Conclusions}

(1) This paper presented both the procedures and results of the finite element simulation of a 3D swinging wear problem for self-lubricating spherical plain bearings. The proposed methods can be used for analyzing the wear mechanisms and predicting the service life of these bearings. It also provides a good reference for simulating all kinds of 3D wear problems.

(2) The self-lubricating spherical plain bearings went through two different stages during the swinging wear process: namely, initial wear stage and stable wear stage. Owing to the increase of the swing times, there was an increase in the friction torque and a decrease in the wear rate. This phenomenon is attributed to the PTFE fibers existing on the fabric surface. These PTFE fibers with small friction coefficient and large wear rate are worn out owing to the development of swinging wear process.

(3) The magnitude of contact pressure in the central contact region was the biggest, and it decreased along both the circumferential and axial directions. Because of the rapid wear in the central contact zone, the maximum contact pressure decreased with increasing of swing numbers.

(4) The maximum wear depth occurred in the central contact region. This was also the location of the wear failure zone. The value of wear depth reached $0.0974 \mathrm{~mm}$ after swinging 25,000 times.

Open Access: The articles published in this journal are distributed under the terms of the Creative Commons Attribution 4.0 International License (http://creativecommons.org/licenses/by/4.0/), which permits unrestricted use, distribution, and reproduction in any medium, provided you give appropriate credit to the original author(s) and the source, provide a link to the Creative Commons license, and indicate if changes were made.

\section{References}

[1] Kim B C, Lee D G. Endurance and performance of a composite spherical bearing. Compos Struct 87(1): 71-79 (2009)

[2] Kim B C, Lee D G. Development of a spherical bearing with uni-directional carbon/epoxy composite. Compos Struct 89(1): 102-109 (2009)

[3] Barbero E J, Trovillion J, Mayugo J A, Sikkil K K. Finite element modeling of plain weave fabrics from photomicrograph measurements. Compos Struct 73(1): 41-52 (2006)

[4] Liu Z L, Shen X J. Study on the elastic properties of the woven fabric liner of spherical plain bearing with selflubricating. Adv Mater Res 139-141: 190-193 (2010)

[5] Ma J, Yang Y L, Qi X W. Tribological performances of fabric self-lubricating liner with different weft densities under severe working conditions. Indian J Fib Text Res 40(3): 293-300 (2015)

[6] Qiu M, Duan C C, Chen L, Li Y C, Hu R S. Effect of clearance on thermodynamic characteristics of woven liner spherical plain bearing. Appl Mech Mater 668-669: 164-167 (2014)

[7] Qiu M, Miao Y W, Li Y C, Lu J J. Influence of ultrasonic modified liners on the adhesive and tribological performances of self-lubricating radial spherical plain bearings. Tribol Trans 59(4): 655-662 (2016)

[8] Park D C, Kim S S, Kim B C, Lee S M, Lee D G. Wear characteristics of carbon-phenolic woven composites mixed with nano-particles. Compos Struct 74(1): 89-98 (2006)

[9] Qiu M, Miao Y W, Li Y C, Lu J J. Film-forming mechanisms for self-lubricating radial spherical plain bearings with hybrid PTFE/aramid fabric liners modified by ultrasonic. Tribol Int 87: 132-138 (2015)

[10] Ren G N, Zhang Z Z, Zhu X T, Men X H, Jiang W, Liu W M. Sliding wear behaviors of Nomex fabric/phenolic composite under dry and water-bathed sliding conditions. Friction 2(3): 264-271 (2014)

[11] Fan B L, Yang Y L, Feng C, Ma J, Tang Y, Dong Y, Qi X W. Tribological properties of fabric self-lubricating liner based on organic montmorillonite (OMMT) reinforced phenolic (PF) nanocomposites as hybrid matrices. Tribol Lett 57(3): 22 (2015)

[12] Zhang Y H, Choi J R, Park S J. Thermal conductivity and thermo-physical properties of nanodiamond-attached exfoliated hexagonal boron nitride/epoxy nanocomposites for microelectronics. Compos Part A 101: 227-236 (2017)

[13] Gu D P, Yang Y L, Qi X W, Deng W, Shi L. Influence of weave structures on the tribological properties of hybrid Kevlar/PTFE fabric composites. Chin J Mech Eng 25(5): 1044-1051 (2012)

[14] Qiu M, Yang Z P, Lu J J, Li Y C, Zhou D W. Influence of step load on tribological properties of self-lubricating radial spherical plain bearings with PTFE fabric liner. Tribol Int 113: 344-353 (2017) 
[15] Zhang Y H, Rhee K Y, Park S J. Nanodiamond nanoclusterdecorated graphene oxide/epoxy nanocomposites with enhanced mechanical behavior and thermal stability. Compos Part B Eng 114: 111-120 (2017)

[16] McColl I R, Ding J, Leen S B. Finite element simulation and experimental validation of fretting wear. Wear 256(11-12): 1114-1127 (2004)

[17] Wang Y F, Yang Z G. Finite element model of erosive wear on ductile and brittle materials. Wear 265(5-6): 871-878 (2008)

[18] Dimaki A V, Dmitriev A I, Menga N, Papangelo A, Ciavarella M, Popov V L. Fast high-resolution simulation of the gross slip wear of axially symmetric contacts. Tribol Trans 59(1): 189-194 (2016)

[19] Põdra P, Andersson S. Finite element analysis wear simulation of a conical spinning contact considering surface topography. Wear 224(1): 13-21 (1999)

[20] Bortoleto E M, Prados E F, Seriacopi V, Fukumasu N K, Da S Lima L G D B, Machado I F, Souza R M. Numerical

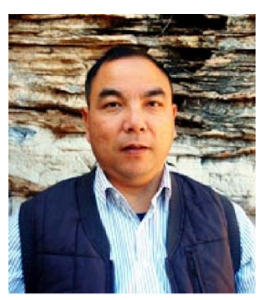

Jigang CHEN. He received his bachelor degree, master degree and $\mathrm{PhD}$ degree from Yanshan University, Qinhuangdao, China, in 1993, 2001 and 2006, respectively. He is a full

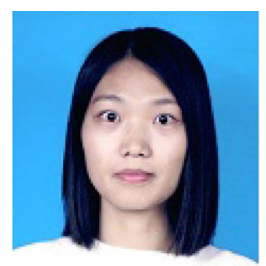

Yahong XUE. She received her master degree in mechanical manufacture and automation in 2015 from Yanshan University, Qinhuangdao, modeling of adhesion and adhesive failure during unidirectional contact between metallic surfaces. Friction 4(3): 217-227 (2016)

[21] Bortoleto E M, Rovani A C, Seriacopi V, Profito F J, Zachariadis D C, Machado I F, Sinatora A, Souza R M. Experimental and numerical analysis of dry contact in the pin on disc test. Wear 301(1-2): 19-26 (2013)

[22] Shen X J, Liu Y F, Cao L, Chen X Y. Numerical simulation of sliding wear for self-lubricating spherical plain bearings. J Mater Res Technol 1(1): 8-12 (2012)

[23] Lu J J, Qiu M, Li Y C. Numerical analysis of selflubricating radial spherical plain bearings and investigations on fatigue damage mechanisms of the liner. Tribol Int 96: 97-108 (2016)

[24] Archard J F. Contact and rubbing of flat surfaces. J Appl Phys 24(8): 981-988 (1953)

[25] Mattei L, Di Puccio F. Influence of the wear partition factor on wear evolution modelling of sliding surfaces. Int J Mech Sci 99: 72-88 (2015)

professor in the School of Yanshan University. His main research areas are precision forming and manufacturing technology of spherical plain bearings, virtual design and manufacture, and aeronautical self-lubricating material research.

China. After then, she was a Ph.D. student in material processing engineering at the same university. Her research interests include material forming and friction of composite materials. 